\title{
Research on Spatial Structure of Urban Innovation Performance in Huaihe Economic Belt
}

\author{
Xu Hai-Ying, Chen Ming-Zhe \\ School of Urban and Environmental Science \\ Huaiyin Normal University \\ Changjiang West Road \\ Huaian, China \\ sqxhy@126.com
}

\begin{abstract}
This article contributes to analyze spatial structure of the innovation performance in Huaihe Economic Belt. We select 11 indexes to construct the evaluation index system for urban innovation performance and make cluster analysis over the innovation performance indexes of the 21 cities in Huaihe Economic Belt. As a result, the 21 cities are divided into four clusters as follows: highest innovation performance, high innovation performance, low innovation performance and the lowest innovation performance. This article analyzes the spatial structure characteristics of the 4 clusters, and draws some conclusions: from the east to the west, the spatial structure shows the rough trend of gradient decrease; the area of high innovation performance in the lower reaches of Huaihe River shows a zonal distribution; the cities with low innovation performance are generally distributed in the middle and upper reaches of Huaihe River.
\end{abstract}

Key words: innovation performance, spatial structure, Huaihe Economic Belt, evaluation index system

\section{Introduction}

With the increasing inputs in innovation, the innovation performance has been developing rapidly in various parts of China. Premier Li Ke-Qiang puts forward 'mass entrepreneurship' and 'all kinds of innovations' at the Davos forum in the summer of 2014. Innovation driving has become an important development strategy for China to build an innovative country. Compared with the developed countries in Europe and America, China relatively lacks innovation resources, and its innovation performance is not high. Innovation performance is an important index to measure the ratio between the input of innovation resources and the output. The study of urban innovation performance is of great significance for the rational allocation of innovative resources, the formulation of innovation driven strategy and the construction of innovative environment.

In 2010, Huaian city of Jiangsu province took the lead in putting forward the strategic idea of constructing 'Huaihe Economic Belt' that regarded Huaian of Jiangsu province, Bengbu-Huainan of Anhui province and Xinyang of Henan province as the core, hoping to build Huaihe River Basin in the region of Northern Jiangsu, Northern Anhui and Southern Henan into a scientific and technological, extroverted and ecotype healthy ecological corridor [2]. The regional scope of Huaihe Economic Belt involves 21 cities in Jiangsu, Anhui and Henan. The whole region faces dual pressure of ecology and economy, and the improvement of innovation performance is an important driving force to achieve regional health and rapid development. Based on the basic concept and connotation of innovation performance, this paper selected 11 indexes to construct the evaluation index system for cities' innovation performance. This paper uses SPSS 19.0 to carry out cluster analysis on the innovation performance indexes of 21 cities in Huaihe Economic Belt. Then, on the basis of the cluster analysis results, this article explores the spatial structure characteristics of the urban innovation performance in Huaihe Economic Belt.

\section{Literature Review}

Many Chinese scholars mainly constructed the index system, and used factor analysis and DEA method to carry out quantitative evaluation, but some of them are not exactly consistent with international standards, such as the source of R\&D funds and the definition of large enterprises. For example, Tang Hou-Xing et.al. use DEA model to analyze and evaluate the regional innovation performance of 28 provinces in China [5]; Gu Shao-Hui et.al. use DEA and SBM methods to measure the scientific and technological innovation level of the Yellow River Economic Belt in 11 provinces and cities[6]; Cheng Zhan-Yong et.al., on the basis of factor analysis, further apply cluster analysis method, to carry out dynamic analysis on the difference of provincial level regional innovation performance[7]. All the above studies have come to a similar conclusion: China's regional innovation performance is generally not high, and the overall innovation output efficiency shows a declining trend.

Based on the study of many scholars at home and abroad [8], we have found that there is no uniform standard in the construction of innovation performance evaluation index system. In the study of spatial scale, the existing fruits have paid more attention to the research of the state and provincial administrative units, and less to the research at the level of the city level, so these researches obviously are of insufficient 
guiding significance for the practical development of regional innovation ability.

\section{Construction of urban Innovation Performance Evaluation System Indexes in Huaihe Eco Economic Belt}

The four aspects: input of innovation resources, technological benefits, economic benefits and social and environmental benefits, can synthetically reflect the level of innovation performance. The evaluation index system of urban innovation performance constructed in this paper adopts the Two Stage Method (TABLE I): the first stage is the input of innovative resources. The input of innovative resources is the premise and foundation of all benefits, and the indexes of representative significance include: various types of professional and technical personnel, the proportion of research and development funds, the number of colleges and universities, the cost of scientific and technological cause, and the number of scientific research institutions. The second stage is the output of various benefits, including scientific and technological benefits, economic benefits and social and environmental benefits. The scientific and technological benefit is an important symbol to measure the success or failure of the scientific and technological activities. The representative indexes include: the number of domestic patent applications authorized and the total achieved value of the high and new technology industry in China. The economic benefit is the improvement of the economic level brought by the output of scientific and technological benefits. The selected representative indexes include: the per capita GDP and the actual utilization of foreign capital throughout the year. The social environmental benefit is an important index of the sustainable development of the city. The selected representative indexes include: the total investment of environmental pollution control and the standard-reaching rate of industrial wastewater discharge.

\section{Innovation Performance Spatial Structure Analysis in Huaihe Economic Belt}

\section{A. Cluster Analysis Results}

This paper carried out cluster analysis on the innovation performance indexes of 21 cities in Huaihe Economic Belt. The initial data are derived from the statistical yearbook of each city in 2017 and the cities' social and economic statistics report in 2016. The initial data was processed according to the same standard. Then, this paper uses SPSS 19.0 between-group linkage method, and divides the 21 cities into four clusters, as shown in TABLE II.

(1)First cluster - Lowest Innovation Performance

The first cluster of city with the lowest innovation performance: Bengbu. Compared with other cities in Huaihe Economic Belt, Bengbu, as the core city in the north of Anhui province, has the lowest innovation performance level, which is manifested in more input of innovative resources and low output. In 2016, the expenditure of science and technology institutions in Bengbu was 1.12203 billion Yuan, the number of scientific research institutions was 401, the number of professional researchers in scientific and technological institutions were 24338, and the manpower and financial input intensity was about several times or even ten times of other cities in Anhui. Its input of innovative resources was at the same level of Xuzhou, Huaian, Yangzhou, Taizhou in Jiangsu province, but the secondary level index in technological benefits: the total output value of high and new technology industry is several times lower than that of Jiangsu. In the social and environmental benefits, the secondary level index: total investment in environmental pollution control was 1.35891 billion Yuan, which is higher than most of the cities in Huaihe Economic Belt. Therefore, Bengbu's innovation performance is at the lowest level in the whole region.

(2)Second cluster - Highest Innovation Performance

The second cluster of city with the highest innovation performance: Yancheng. Compared with other cities in Huaihe Economic Belt, Yancheng has the highest level of innovation performance, which is manifested in the high input of innovative resources and the high output of various benefits. In 2016, the expenditure of science and technology institutions in Yancheng was 1.97879 billion Yuan, the number of scientific research institutions was 1401, the number of ordinary colleges and universities was 5 , the number of professional research personnel in the scientific research institutions was 26866, and the input of manpower and financial resources was at the first place in the Huaihe Economic Belt. In the secondary level indexes of science and technology benefits, the total value of high and new technology industry reached 304.4 billion Yuan, and the number of granted patents reached 7840 in the whole year. The secondary level index in the economic benefit: per capita GDP reached 58299 Yuan, and the actual utilization of foreign capital reached US $\$ 795$ million in the whole year. Compared with other cities in Huaihe Economic Belt, the overall data was at the forefront in the whole Huaihe Economic Belt. Therefore, the level of innovation performance in Yancheng is at the highest level in the whole region.

(3)Third cluster - High Innovation Performance

The third type of cities with high innovation performance: Xuzhou, Suqian, Huaian, Yangzhou, Taizhou, Huainan and Nanyang, total of 7 cities. The innovation performance of these seven cities is at a relatively high level, which shows that the input of innovation resources is directly proportional to the benefits, that is, the higher the input of innovative resources is, the higher the output will be. In 2016, the 7 cities ranked in the forefront of the whole Huaihe Economic Belt in terms of innovation resources input; the manpower and financial input were several times higher than those in the upper and middle reaches of Huaihe Economic Belt. The total amount of expenditure of science and technology institutions of the 7 cities in the secondary level index accounts for about $50 \%$ of total of the overall Huaihe Economic Belt, and the number of scientific research institutions and the number of research professionals are at the forefront of the whole economic belt. In terms of science and technology benefits, the secondary index: the total output value of the new and high technology industry in the 7 cities was 1.825039 trillion Yuan, accounting for $64 \%$ of the total output value of Huaihe Economic Belt. In terms of economic benefit, the average GDP per capita in the 7 cities was 55940 Yuan, which was 1.44 times the average of the whole economic belt. In terms of social environmental benefits, the secondary level index: the total amount of environmental pollution control was 2.2667237 billion Yuan, accounting for 


\section{Recent Developments on Information and Communication Technology (ICT) Engineering- Meen, Yang \& Zhao ISBN: 978-981-14-2136-5}

$29 \%$ of the total of Huaihe Economic Belt. Therefore, the innovation performance of these 7 cities is at a high level in the whole economic belt.

(4)Fourth cluster: Low Innovation Performance

The fourth cluster of cities with low innovation performance: Pingdingshan, Zhoukou, Zhumadian, Luohe, Bozhou, Shangqiu, Huaibei, Suzhou, Chuzhou, Xinyang, Liu'an and Fuyang, total of 12 cities; the common point of these cities is the ordinary level of economic strength and less scientific and technological input. This is showed by fact that the secondary level indexes (expenditure of science and technology institutions, number of scientific research institutions and number of professional personnel in scientific research institutions) are low-ranking in all the cities in Huaihe Economic Belt. The secondary index in the scientific and technological benefits: the total output values of high and new technology industry in 10 cities were all lower than 100 billion Yuan (the output values of Luohe and Chuzhou were respectively 129.683 billion Yuan and 119.590 billion Yuan), and the total output values of high and new technology industry in some cities were even less than 50 billion Yuan, showing a significant drop, ranking at the bottom in the whole economic belt. In terms of the secondary level index: the number of granted patents, the 5 cities: Luohe, Shangqiu, Xinyang, Zhoukou and Zhumadian have less than 1000 patents all year round. In terms of the secondary index in economic benefits: the per capita GDP, the average value of these 12 cities was 26879 Yuan, which was $69 \%$ of the average value of the whole Huaihe Economic Belt; the living standard of the residents is low, and the quality is poor. As for the secondary index of social benefits: total expenditure on environmental pollution control, Zhoukou and Suzhou were at the bottom, and the other 9 cities also rank near the bottom.

\section{B. Spatial Structure Characteristics of Cities' Innovation Performance in Huaihe Economic Belt}

We analyze the spatial characteristics of the four types of cities, and find that:

(1) The spatial characteristics show a rough gradient decline trend from the east to the west. From the point of view of spatial structure, the innovation performance of the economic belt is generally hierarchical from east to west. Yancheng city in the east side is the city with the highest innovation performance; its output value of high and new technology industries, number of colleges and universities and the number of scientific research institutions and other indexes are excellent. Yancheng is located in the superposition area of the two major national development strategies: Jiangsu Coastal Grand Development and Yangtze River Delta City Group, and has obvious geographical advantages. Moreover, Yancheng has large area, rich resources and convenient transportation. It is a city with great potential for development.

(2) The cities with high innovation performance show vertical zonal distribution. In the 7 cities with high innovation performance, 5 cities are located in Jiangsu Province, and at the lower reaches of Huaihe River; they have convenient longitudinal traffic conditions; at the same time, as influenced by the administrative division, the innovation elements flow smoothly in the longitudinal direction. In addition, Huainan city in the north of Anhui province and Nanyang city in the south of Henan are the only cities with higher innovation performance in the upper and middle reaches of Huaihe River. Nanyang's investment in innovation was not high, but technical gains rank first in Henan. Huainan's investment in innovation was high and its science and technology benefit and economic benefit rank high.

(3) The cities with low innovation performance are generally located in the upper and middle reaches of Huaihe Economic Belt. The 11 cities with low innovation performance belong to Anhui and Henan, and they are located in the upper and middle reaches of Huaihe Economic Belt. These cities are located in the inland areas of central China, and their economic development speed is obviously lagging behind the eastern coastal cities. The construction of transportation network is relatively backward, and there is a lack of intercity communication. In addition, the historical factors also caused this region mainly engages in agriculture industry and the development of industry and commerce is slow; the frequent droughts and droughts in Huaihe River basin have caused great damage to the regional economy. Therefore, the regional economy cannot support the high investment of innovative resources; the backward economic development model causes the scientific and technical benefits, the economic benefits and the social environmental benefits cannot be improved, resulting in a vicious circle; the innovation performance of these cities maintained at a low level for a long time.

\section{Summary and Implications}

Through the construction of the evaluation index system for the cities' innovation performance and the use of cluster analysis and spatial structure analysis, this paper explored the spatial structure of cities' innovation performance in Huaihe Economic Belt, and has drawn the following conclusions: from the results of cluster analysis, the innovation performance level of the 21 cities in Huaihe Economic Belt is quite different; through cluster analysis, we can divide the 21 cities in Huaihe Economic Belt into four types: the highest innovation performance, the lowest innovation performance, high innovation performance and low innovation performance. In terms of spatial structure, the innovation performance shows a roughly decreasing trend from the east to the west; the cities with higher level of innovation performance shows the characteristics of zonal distribution; the cities with lower innovation performance are mainly concentrated in Henan and Anhui provinces in the middle and lower reaches of Huaihe River.

Based on the above research conclusions, this paper believes that we should pay attention to the following problems if we need to greatly improve the innovative level of Huaihe Economic Belt: (1) break the traffic block from east to west to promote the highly efficient flow of innovation elements in the region. In the whole Huaihe Economic Belt, there are almost no fast channels between the core cities respectively in the upstream and downstream, and this has become the biggest bottleneck in the integration of Huaihe River Basin. Therefore, it is necessary to create multiple fast channels along Huaihe River, to enhance the highly efficient flow of innovative elements within this region. These channels should include: the 
railway along Huaihe River, the expressways along Huaihe River, Huaihe River golden waterway, the high speed railway along Huaihe River and the airport groups [9]. (2) Increase investment and cultivate the three core cities into important innovative node cities. As the first city to put forward the strategy of Huaihe Economic Belt, Huaian of Jiangsu province proposed to focus on the development of three major node cities: Xinyang of Henan province, Bengbu of Anhui province, Huaian of Jiangsu province; in terms of geographical locations, the three cities are respectively located in the central places of the upper, middle and lower reaches of Huaihe River. It is of great significance to cultivate the three core cities into important innovative node cities, and let them radiate the surrounding areas to help improve their innovation capability. The horizontal links between the three cities can connect all the cities of Huaihe Economic Belt into a compact urban belt, which is conducive to promoting regional coordinated development. (3) For the regions with lower innovation performance in north of Anhui and south of Henan provinces, they should focus on the development of Huainan and Nanyang that have higher innovation performance, and should increase their investment and cultivate them into the secondary level innovative cities in the middle and lower reaches of Huaihe River.

\section{Acknowledgement}

We'd like to acknowledge the funding of the national Science foundation (41371136).

TABLE I

EVALUTION SYSTEM INDEXES URBAN OF INNOVATION PREFORMANCE

\begin{tabular}{|c|c|}
\hline 1st level index & 2nd level index \\
\hline $\begin{array}{l}\text { inputs of } \\
\text { innovation } \\
\text { resources }\end{array}$ & $\begin{array}{l}\text { the number of professional and technical personnel (X1) } \\
\text { the number of scientific research institutions (X2) } \\
\text { the proportion of R\&D funds to GDP(X3) } \\
\text { the cost of scientific and technological cause (X4) } \\
\text { the number of colleges and universities (X5) }\end{array}$ \\
\hline $\begin{array}{l}\text { technological } \\
\text { benefits } \\
\text { economic benefits } \\
\text { social and } \\
\text { environmental } \\
\text { benefits }\end{array}$ & $\begin{array}{l}\text { the number of domestic patent applications authorized (X6) } \\
\text { the total achieved value of the high and new technology industry (X7) } \\
\text { the per capita GDP (X8) } \\
\text { the actual utilization of foreign capital throughout the year (X9) } \\
\text { the total investment of environmental pollution control (X10) } \\
\text { the standard-reaching rate of industrial wastewater discharge (X11) }\end{array}$ \\
\hline
\end{tabular}

TABLE II

CLUSTER ANALYSIS RESULTS

\begin{tabular}{|c|c|c|}
\hline Cluster & $\begin{array}{c}\text { Innovation } \\
\text { performance }\end{array}$ & City \\
\hline Cluster 1 & $\begin{array}{l}\text { Lowest Innovation } \\
\text { Performance }\end{array}$ & Bengbu \\
\hline Cluster 2 & $\begin{array}{l}\text { Highest Innovation } \\
\text { Performance }\end{array}$ & Yancheng \\
\hline Cluster 3 & $\begin{array}{l}\text { high Innovation } \\
\text { Performance }\end{array}$ & $\begin{array}{l}\text { Xuzhou, Suqian, Huaian, Yanzhou,Taizhou, } \\
\text { Huainan,Nanyang }\end{array}$ \\
\hline Cluster 4 & $\begin{array}{l}\text { Low Innovation } \\
\text { Performance }\end{array}$ & $\begin{array}{l}\text { Pingdingshan,Zhumadian,Luohe,Haozhou,Shangqiu,Huai } \\
\text { bei,Suzhou,Chuzhou,Xinyang,Liuan,Fuyang }\end{array}$ \\
\hline
\end{tabular}

\section{References}

[1] X. Wang, Research on Xinjiang's Scientific and Technological Innovation Ability and its Performance Evaluation, Wulumuqi: Master's Degree Thesis of Xinjiang University, 2010, pp.50-51.

[2]W. Huang, Performance Evaluation, Analysis of Influencing Factors and Countermeasures for Transformation of Scientific and Technological Achievements in China, Changchun: Master's Degree Thesis of Jilin University, 2013, pp.25-28.

[3]R. Nelson, "Technology, institutions and innovation Systems", Research Policy, 2002,31(2):265-272.

$[4] \mathrm{H}$. Wu, W. Yang, J. Lei, "New progress and prospect of overseas regional innovation system research", Science Research Management, 2011 (5): 1 - 4.

[5]L. Yan, "Comprehensive evaluation system and empirical application of urban innovation performance", Economic Geography, 2011 (9): 1470 -1476.

[6] K. Xie, S. Zhao, "Chen. Evaluation of regional innovation performance of typical central cities in China", Technology and Economy, 2011 (10): 22 - 26.

[7]Y. Liu, Z. Wang, F. Wu, "Empirical analysis of comprehensive evaluation of urban innovation capability", Urban Development, 2010 (9): 30 - 35.

[8]F. Gong, L. Wen, "Research on comprehensive evaluation of scientific and technological innovation performance in Neimonggu', Resource Development and Market, 2015, (9): $1031-1035$.

[9]H. Dan, "Comprehensive fuzzy evaluation of enterprise technological innovation performance and its application", Scientific Research Management, 2012 (6): 120 - 125. 